\title{
On the Road to Immunotherapy-Prospects for Treating Head and Neck Cancers With Checkpoint Inhibitor Antibodies
}

\author{
Frank J. Ward ${ }^{1 *}$, Lekh N. Dahal ${ }^{2}$ and Rasha Abu-Eid ${ }^{1,3}$ \\ ${ }^{1}$ Institute of Medical Sciences, School of Medicine, Medical Sciences and Nutrition, University of Aberdeen, Foresterhill, \\ Aberdeen, United Kingdom, ${ }^{2}$ Centre for Cancer Immunology, Faculty of Medicine, University of Southampton, Southampton \\ General Hospital, Southampton, United Kingdom, ${ }^{3}$ Institute of Dentistry, School of Medicine, Medical Sciences and Nutrition, \\ University of Aberdeen, Foresterhill, Aberdeen, United Kingdom
}

\section{OPEN ACCESS}

Edited by:

Fabrizio Mattei,

Istituto Superiore di Sanità (ISS), Italy

Reviewed by:

Elizabeth Ann Repasky,

Roswell Park Cancer Institute,

United States

Kawaljit Kaur,

University of California, Los Angeles,

United States

Rodabe N. Amaria,

University of Texas MD Anderson

Cancer Center, United States

Roberto Pili,

Indiana University, United States

${ }^{*}$ Correspondence:

Frank J. Ward

mmd475@abdn.ac.uk

Specialty section:

This article was submitted to

Cancer Immunity and Immunotherapy,

a section of the journal

Frontiers in Immunology

Received: 05 May 2018 Accepted: 04 September 2018

Published: 24 September 2018

Citation:

Ward FJ, Dahal LN and Abu-Eid $R$

(2018) On the Road to

Immunotherapy-Prospects for

Treating Head and Neck Cancers With

Checkpoint Inhibitor Antibodies.

Front. Immunol. 9:2182.

doi: 10.3389/fimmu.2018.02182
Head and neck cancers (HNC) represent a heterogeneous cluster of aggressive malignancies that account for $3 \%$ of all cancer cases in the UK. HNC is increasing in frequency particularly in the developing world, which is related to changes in risk factors. Unfortunately, the mortality rate is high, which is chiefly attributed to late diagnosis at stages where traditional treatments fail. Cancer immunotherapy has achieved great successes in anti-tumor therapy. Checkpoint inhibitor $(\mathrm{Cl})$ antibodies enhance anti-tumor activity by blocking inhibitory receptors to drive tumor-specific T and NK cell effector responses. Since their introduction in 2011, Cl antibodies have been approved for many cancer types including HNC. Here, we examine the development of $\mathrm{Cl}$ therapies and look forward to future developments for treatment of $\mathrm{HNC}$ with $\mathrm{Cl}$ therapies.

Keywords: head and neck squamous cell carcinoma, checkpoint inhibitor, immunotherapy, T cells, PD-1

\section{INTRODUCTION}

The notion of boosting anti-tumor immunity as a means of treating cancer has been escalated by the recent unveiling of exciting new immunotherapies including the checkpoint inhibitor (CI) antibodies (1). CI antibodies selectively activate adaptive immunity to locate and obliterate tumors anywhere in the body and can also generate an enduring disease remission (2). The recent approval of six CI antibody therapies for treating a range of cancers (3-8) heralds a golden age of immunotherapy, with the promise of further novel, better immune-boosting technologies and combination treatment strategies to come (9). But there are also caveats such as poor patient response frequency, the potential for serious immune related side effects and generally a lack of biomarkers which can guide the use of these therapies (10). In this review, we reflect on the developing prospects for CI therapy to treat head and neck cancers (HNC).

\section{HEAD AND NECK CANCERS}

Head and neck cancers, of which the majority are squamous cell carcinomas (HNSCC), represent a collection of neoplasms that are difficult to treat and whose incidence in the UK and worldwide has increased by around 30\% since 1990. In 2015, 12,000 individuals were diagnosed with HNC in the UK [CRUK, oral cancer statistics, 2018], representing 3\% of all cancers. Annually, there is an estimated 600,000 cases worldwide, which affect the oral cavity, oropharyngeal, hypopharyngeal, 
and laryngeal tissues $(11,12)$. Increased incidence is associated with known risk factors including high use of both tobacco and alcohol. In certain parts of the world, in particular South East Asia, the incidence of HNC is much higher and is reported as high as $30 \%$ of all cancers in India, with the major risk factor being betel quid (pan) chewing in all its forms, which almost invariably includes tobacco (smokeless tobacco) $(11,12)$. Many cases of HNC are also associated with infection by human papillomavirus (HPV) strains 16 and 18, well established highrisk viral types in other malignancies, most notably cervical cancer (13). Patients with $\mathrm{HPV}^{+}$tumors, however, have a better outcome in terms of both survival and reduced risk of recurrence compared with HNC in which no virus can be detected (13). This latter observation may reflect a greater intrinsic immunogenicity associated with HPV infection and this perception is supported by immune profiling studies that find increased effector $\mathrm{T}$ cell infiltrates in $\mathrm{HPV}^{+}$compared with $\mathrm{HPV}^{-}$tumors (14).

The current treatment standard of care for HNSCC is to treat recurring or metastatic tumors with cetuximab, an anti-epidermal growth factor receptor antibody, together with platinum based cis- or carboplatin chemotherapy plus 5flurouracil and methotrexate, which is further supported where appropriate by surgery and radiotherapy (15), and in some instances augmented by the taxanes, docetaxel and paclitaxel.

In 2016, two anti-PD-1 checkpoint inhibitor monoclonal antibodies (mAbs), pembrolizumab and nivolumab provided new options for cisplatin resistant recurring or metastatic HNSCC following accelerated FDA approval based on encouraging clinical trial data $(16,17)$ and precedence of response efficacy in large phase III clinical trials of melanoma and non-small cell lung cancer in which both antibodies had already demonstrated significant improvements in patient outcomes compared to current standard of care therapy $(4,5,18,19)$. This has led to further clinical trials for HNSCC with larger patient cohorts primarily with the aim of comparing anti-PD-1 antibodies alone or together with current platinumbased therapies and cetuximab. Currently, there are more than 90 clinical trials involving established CI inhibitor therapies and HNSCC.

\section{IMMUNE CHECKPOINTS}

The immune system is a decision-making entity which, when not required remains quiescent but vigilant for the emergence of a new pathogenic challenge. Once that challenge arrives, the immune system ramps up immune processes shaped to deal specifically with each new pathogenic threat, powerful enough to clear the pathogen, but which may also carry some risk of bystander damage to host cells and tissues. After pathogen clearance, the immune system also needs to return to its former quiescent state to avoid any further damage. Immune checkpoints, primarily receptors on immune cells, regulate both immune response intensity to prevent host tissue damage, and also resolve the immune response after pathogen clearance (20). Interactions between checkpoint receptors and their ligands can be restricted to immune cell subsets but can also take place between immune and non-immune cells (21). Environmental cues within an inflammatory lesion up-regulate expression of receptors on non-hematopoietic and non-lymphoidal cells such as epithelia that then engage with immune effector cells to suppress and eventually quell their activity $(22,23)$.

There are several immune checkpoint receptors, all of which have individual expression patterns on a variety of immune cells and, therefore, contribute to immunoregulation at different levels. Perhaps the best known and most fundamental checkpoint receptor is CTLA-4 (CD152) (24), which plays a role both in the priming of naïve $\mathrm{T}$ cells and also control of effector $\mathrm{T}$ cell response intensity (25-27). Other checkpoints include PD1 (CD279) (28, 29), ICOS (CD278) (30), 4-1BB (CD137) (31), OX40 (CD134) (32), LAG-3 (CD223) (33), TIM-3 (34), TIGIT (35), VISTA (36), BTLA (CD272) (37), and GITR (38), which display a hierarchy of expression on different cell types and therefore exert a more selective control over interactions both between immune cell subsets and between immune and nonimmune cells (39). Analyses of immunogenic HNSCC, suggest that in many individuals the tumors appear "primed" to make potent anti-tumor effector $\mathrm{T}$ cell responses and can therefore be considered suitable for CI therapy. There is an urgent need, therefore, to develop genetic and histological response biomarkers that efficiently identify and stratify responsive patient cohorts to one or more of these CI therapies, together with other therapies designed to increase tumor immunogenicity $(40,41)$.

\section{CHECKPOINT INHIBITOR ANTIBODIES}

Checkpoint inhibitor (CI) antibodies target immune cell checkpoint receptors to selectively activate antigen-specific antitumor $\mathrm{T}$ cell responses. In 2013, CI therapies together with CAR-T cell immunotherapy were considered to be the most important scientific breakthrough of the year by Science (42). The efficacy of CI therapies has been ground-breaking in the treatment of melanoma, non-small cell lung cancer (NSCLC) and other cancers, including HNSCC, offering clear advances over other established chemo- and immunotherapies in terms of patient response frequency, as well as efficacy and durability of response. In general, tumor immunogenicity is considered to be the most important factor in determining whether or not a particular type of cancer will respond to CI therapy (43), but this has not prevented CI therapies from being tested in most types of cancer in ongoing clinical trials and it will be some time before it becomes apparent which cancers are most responsive to this type of CI immunotherapy.

The six CI antibodies with FDA approval so far have specificities for CTLA-4 (ipilimumab), PD-1 (pembrolizumab, nivolumab) and PD-L1 (atezolizumab, durvalumab, and avelumab) checkpoint receptors. Collectively, they have been approved for advanced melanoma, non-small cell lung cancer, renal cell carcinoma, urothelial and bladder cancer, HNSCC, metastatic Merkel cell carcinoma, refractory classical Hodgkin lymphoma and gastric cancer (Figures 1-3). Another CTLA-4 antibody, tremelimumab, is in advanced stages of clinical trials, while cemiplimab an anti-PD-1 $\mathrm{IgG}_{4}$ antibody is likely to be 


\section{Anti-CTLA-4 antibody \\ Ipilimumab}

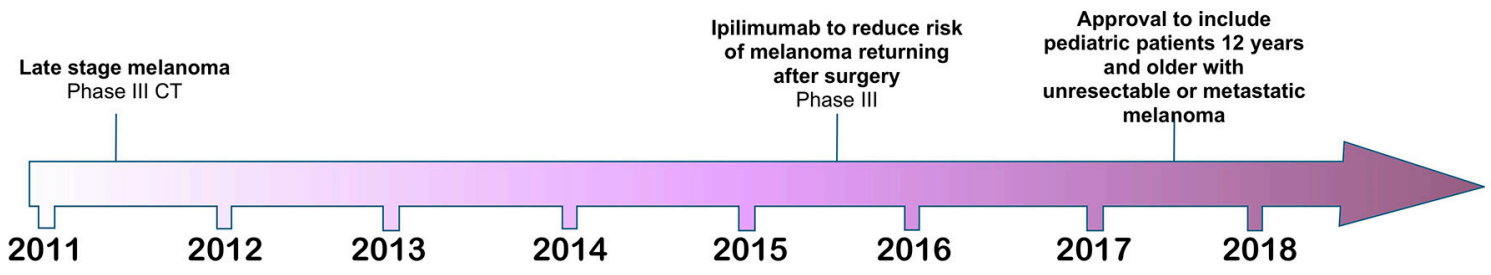

FIGURE 1 | Time line of FDA approvals for ipilimumab (July 2018).

\section{Anti-PD-1 antibodies}

\section{Pembrolizumab}

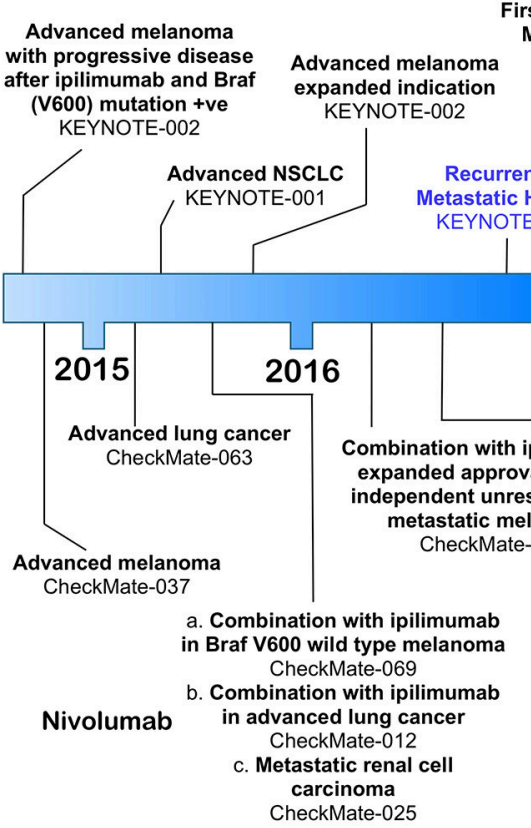

a. 1st line combination therapy for KEYNOTE-021

b. Locally advanced or metastatic urothelial cancer

c. Any solid tumor carrying the MSI$\mathrm{H}$ genetic feature st line treatment for etastatic NSCLC H genetic feature
KEYNOTE-024 KEYNOTE-016 -164 -012 -028 \& -158 metastatic non-squamous NSCLC a. Previously treated recurrent or metastatic cervical cancer whose tumors express PD-L1 KEYNOTE-158 b.Refractory or relapsed primary mediastinal large $B$ Cell Lymphoma (PMBCL) KEYNOTE-170 (c)

Recurrent locally advanced or metastatic
PD-L1+ gastric or gastroesophagea Junction cancer Junction cancer
KEYNOTE-059
HNSCC TE-012
Classical Hodgk

-

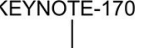




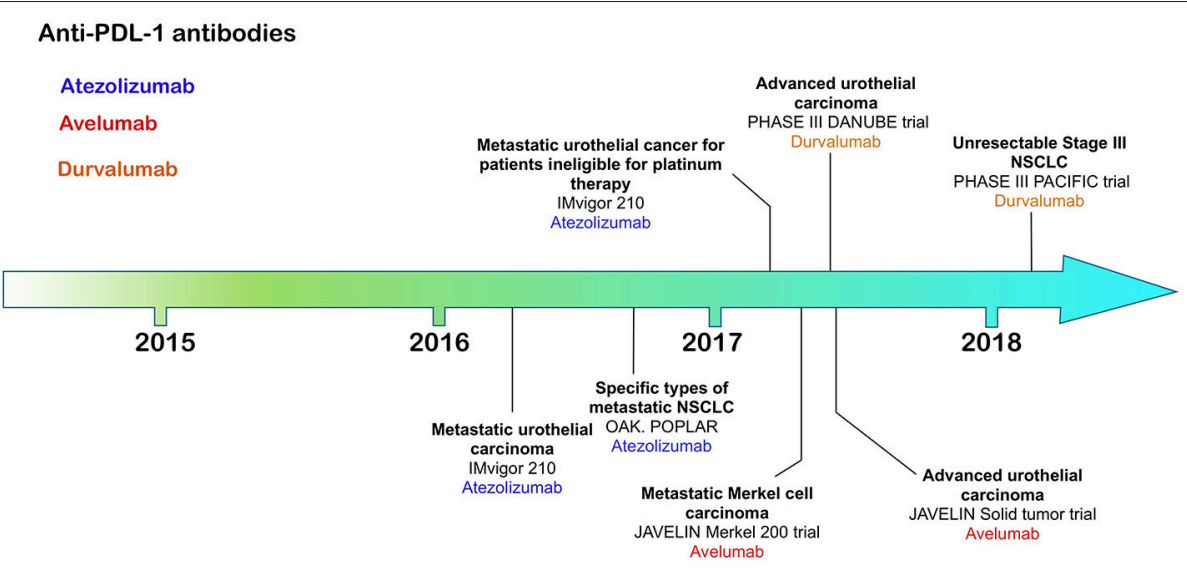

FIGURE 3 | Time line of FDA approvals for anti-PD-L1 antibodies Atezolizumab, Avelumab, and Durvalumab (July 2018).

priming of naïve $\mathrm{T}$ cells, inducing full activation and expansion of nascent effector $\mathrm{T}$ cell populations against tumor neoantigens (48).

The non-redundant function of CTLA-4 in regulating immune cell homeostasis was demonstrated by CTLA-4 knockout mice, which die soon after birth from massive lymphocytic infiltration of tissues and organs $(49,50)$. Healthy homeostasis in these mice could be restored, however, by infusion of recombinant soluble CTLA4-Ig (51) or by generating chimeric mice in which CTLA $-4^{+}$T cells are able to regulate CTLA- $4^{-} \mathrm{T}$ cells to prevent their unregulated expansion $(52,53)$. In humans, analyses of heterozygous CTLA-4 gene haploinsufficiencies, or reduced expression of CTLA- 4 caused by mutation in the LRBA gene (encoding the lipopolysaccharide-responsive and beigelike anchor protein), which is thought to regulate CTLA-4 protein turnover (54), have also revealed complex pathological phenotypes that correspond to unregulated $\mathrm{T}$ cell responses, including Treg dysfunction, effector $\mathrm{T}$ cell hyper-proliferation, non-lymphoid organ infiltration and autoantibody production $(55,56)$. Patients with these pathologies also respond well to abatacept, the human recombinant soluble CTLA4-Ig. These observations demonstrate that CTLA- 4 can be used by immune cells to extrinsically regulate effector $\mathrm{T}$ cell populations. CTLA4 is constitutively expressed in higher amounts on regulatory $\mathrm{T}$ cells (Treg) and is essential for their immunoregulatory function (57), although how these cells utilize CTLA-4 to control effector T cell populations still needs to be fully elucidated (58).

The therapeutic potential of CTLA-4 antibody blockade was first demonstrated in murine cancer models of melanoma, mammary and prostate cancer (59-61). In the B16-BL6 and B16-F10 murine models of solid and metastatic melanoma, in particular, anti-CTLA-4 antibody blockade of T cells alone was not effective in eliminating tumors, and their potential for driving anti-tumor immunity was revealed only after treatment of the mice with a granulocyte/macrophage colony-stimulating factor (GM-CSF)-expressing tumor cell vaccine, which enhanced dendritic cell activity and also enhanced the generation of B16 melanoma-specific T cells (60). This increase in immunogenicity provided the antigen required by tumor specific effector $\mathrm{T}$ cells, allowing complete dissolution of the tumors. These experiments in mice shaped the future therapeutic strategy for CI blockade in humans and it also highlighted the requirement for tumor immunogenicity as an essential requirement for successful treatment. These early experiments in CI therapy highlighted the importance of the mechanisms and environmental cues that drive the release and display of tumor associated and tumor specific neoantigens (62).

Ipilimumab was approved by the FDA in 2011 for use in metastatic melanoma refractory to conventional treatments, in which patients receiving ipilimumab with or without the melanoma-derived gp 100 tumor-associated antigenic peptide covaccine demonstrated increased overall survival of 10 months compared with 6.4 months in patients receiving the vaccine alone (3). An interesting and important feature of ipilimumab CI therapy is that it can induce an enduring remission from melanoma disease in approximately $22 \%$ of metastatic melanoma patients receiving the therapy (2). Despite this success, ipilimumab has little beneficial effect for most patients receiving it and it can also provoke very severe immune related adverse events, including dermatitis, colitis, hypophysitis, and other inflammatory events (3). Further, there is currently no reliable biomarker with which to stratify patients by identifying those responsive to the therapy. Ipilimumab is generally administered four times over a period of approximately 3 months at a dose of 3 or $10 \mathrm{mg} / \mathrm{kg}$ body weight.

Despite the ground-breaking success of ipilimumab as the first CI therapy, there is still some controversy of how it is able to "release the brakes" of the immune system to drive antitumor immunity. Although the simple hypothesis is that CTLA4 blockade generally inhibits CTLA-4 engagement with its B7 ligands, thereby allowing CD28 costimulation and full $\mathrm{T}$ cell activation to take place, there is some evidence that other factors may also be at play. Currently, the best accepted hypothesis is that anti-CTLA-4 antibodies mediate at least some of their immune boosting effects by engaging with activating Fc gamma receptors $(\mathrm{F} c \gamma \mathrm{R})$ by binding to CTLA-4 on Treg to induce macrophage 
mediated depletion of the Treg through antibody-dependent cellmediated cytotoxicity (ADCC) within the tumor environment or at the infusion site (63). This depletion would therefore allow reactivation of tumor infiltrating lymphocytes (TIL) to drive productive anti-tumor immunity. Other groups have provided evidence that anti-CTLA- 4 antibodies can directly engage with CTLA- $4^{+}$tumor cells to drive $\operatorname{ADCC}(64,65)$, but this is unlikely to fully explain the profound anti-tumor effects of CTLA- 4 based CI therapy.

No CTLA-4 based CI therapy has been approved for the treatment of HNSCC but there are several clinical trials underway involving either ipilimumab or tremelimumab. Almost all of these are clinical trials involving combinations of anti-CTLA-4 mAbs either with other CI therapies, or current standard of care HNSCC therapies such as cisplatin and cetuximab.

\section{PD-1/PD-L1}

Programmed death-1 (PD-1) is a checkpoint receptor primarily expressed by $\mathrm{T}$ cells that plays a crucial role in regulating and resolving adaptive effector $\mathrm{T}$ cell immune responses (28). PD1 binds two ligands PD-L1 (CD274, B7-H1) (66) and PD-L2 (CD273, B7-DC) (67). PD-L1, has a very broad distribution on normal tissues and PD-1: PD-L1 interactions between immune and non-immune cells within inflammatory milieus are thought to maintain peripheral tolerance by suppressing effector $\mathrm{T}$ cell responses $(68,69)$. Induction of signaling through the PD1 receptor suppresses IL-2 production in $\mathrm{T}$ cells and renders them less antigen-responsive (70). This anergic "exhaustion" phenotype is reversible by selective blockade of either PD-1 or PD-L1 (71). PD-L2 expression is less abundant and restricted mainly to professional antigen presenting cells but induces similar effects in T cells (72).

The therapeutic benefits of CTLA- 4 antibody blockade were identified in murine tumor models, but the potential for PD-1 or PD-L1 blockade as a novel CI therapy arose from observational studies in humans. Soon after initial identification of PD-L1, analysis of renal cell carcinoma (RCC) patient survival outcomes following nephrectomy identified that patients with high expression levels of PD-L1 on either RCC tumor cells, RCC tumor infiltrating lymphocytes, or both, were at significantly increased risk of death from aggressive tumor progression (73). This important observation, together with extensive analyses of PD-L1 on tumor cell lines (67) and tumors including HNSCC (74), raised the notion of a novel immune evasion mechanism through which cancer cells nullify antitumor effector $\mathrm{T}$ cell responses by engaging PD-1 and inducing the exhaustion phenotype (75). These latter observations in HNSCC were further qualified by more recent studies in which analysis by PCR and immunohistochemistry of 41 esophagectomy tumors identified elevated levels of PD-L1 to be associated with a poor prognosis particularly in advanced tumors (76), while another study, however, did not find a clear correlation between tumor cell expression of PD-L1 and poor prognosis, but did identify elevated expression of PD-L1 on infiltrating immune cells, including $\mathrm{T}$ cells, macrophages and dendritic cells, to correlate significantly with increased overall survival (77). In addition, increased abundance of $\mathrm{CD}^{+}$and $\mathrm{CD}^{+} \mathrm{T}$ cell infiltrates also associated with prolonged survival outcomes (77).

With regard to $\mathrm{HPV}^{+}$tumors, the $\mathrm{PD}-1: \mathrm{PD}-\mathrm{L} 1$ nexus may be especially relevant given that the effector $\mathrm{T}$ cell exhaustion phenotype, induced by engagement of PD-1 with PD-L1, is often associated with viral infection (70), and is likely a critical element in the induction of an artificial immune privileged microenvironment (78). $\mathrm{HPV}^{+}$oropharyngeal tumors are associated with increased levels of $\mathrm{T}$ cell infiltrates and following conventional therapy overall survival and reoccurrence are both improved compared with $\mathrm{HPV}^{-}$tumors $(77,79)$ suggesting that they are in effect primed for an anti-tumor response because of the anti-viral response. However, although HPV positive status signals a better outcome for HNSCC, recent studies investigating HPV integration into the host genome suggest that HPV integration into key gene sites including the PD-L1 gene may be a critical marker for patient outcome with reduced survival in patients with integration positive HPV tumors (13).

These studies have led to the rapid development of both antiPD-1 and anti-PD-L1 checkpoint inhibitor therapies to block the PD-1: PD-L1 axis, which have since demonstrated significant improvements in patient outcomes in clinical trials for a range of cancers including HNC over the last five years.

Antibodies specific for the PD-1 receptor were the first CI therapies to be introduced after ipilimumab, initially for the treatment of melanoma, and have had much greater success than ipilimumab clinically and commercially. In 2017, sales of Keytruda $^{\mathrm{TM}}$ (pembrolizumab) and Opdivo ${ }^{\mathrm{TM}}$ (nivolumab) were reported as $\$ 3.8$ billion and $\$ 4.95$ billion respectively with worldwide growth in sales from 2016 to 2017 of 171 and $31 \%$ respectively. Because $\mathrm{CI}$ therapies, including the $\mathrm{PD}-1$ antibodies, target the immune system rather than the tumor, CI antibodies can theoretically be used to treat many forms of cancer and this notion has been successfully translated into the clinic with regard to anti-PD-1.

Unlike the view of anti-CTLA-4 antibodies in which binding $\mathrm{Fc} \gamma \mathrm{R}$ may indirectly contribute to their therapeutic effects, antiPD-1 mAbs are mechanistically straightforward and function simply by blocking engagement of PD-1 with its ligands PD-L1 and PD-L2. Indeed, engagement of $F c \gamma R$ was detrimental to their therapeutic potency (80) and thus most anti-PD-1 antibodies are of the $\mathrm{IgG}_{4}$ antibody subclass, which has weak binding associations with $\mathrm{Fc} \gamma \mathrm{R}$.

So far, the anti-PD-1 antibodies have been FDA approved for the treatment of advanced melanoma, non-small cell lung cancer, renal cell carcinoma, classical Hodgkin's lymphoma, urothelial cancer, gastric cancer and head and neck cancer (Figure 2). Throughout clinical trials, anti-PD-1 antibodies demonstrated an increase in response frequency in patients compared with current standard of care and were accompanied by lower risk and frequency of serious immune related adverse events compared with ipilimumab (81). Both pembrolizumab and nivolumab were first approved for use by the FDA after being granted an accelerated approval protocol in 2014 for the treatment of 
unresectable metastatic melanoma in patients carrying the V600 BRAF mutation $(5,82)$.

\section{ANTI-PD-1 THERAPY IN HNSCC}

Pembrolizumab, a humanized $\mathrm{IgG}_{4}$ antibody was approved on August 5th, 2016 under the FDA's accelerated approval programme, based on data from the KEYNOTE-012 phase $1 \mathrm{~b}$ clinical trial, which assessed the therapeutic effects of pembrolizumab in patients with HNSCC, triple negative breast cancer, gastric cancer and urothelial cancer (16). HNSCC patients whose disease had progressed following platinum-based therapy received pembrolizumab at either $10 \mathrm{mg} / \mathrm{kg}$ body weight every 2 weeks $(n=53)$ or a fixed dose of $200 \mathrm{mg}$ every 3 weeks $(n=$ 121) until disease progression or the development of intolerable toxicity (16). Patients received treatment for a maximum of 24 months. The overall response rate in the combined HNSCC patient cohorts was 16 with $5 \%$ of those achieving a complete response. The duration of response in $82 \%$ of the responsive patients lasted more than 6 months. Pembrolizumab has also shown clinically significant activity in patients with both $\mathrm{HPV}^{+}$ or $\mathrm{HPV}^{-}$tumors (83). Among the immune related adverse events associated with therapy were pneumonitis, colitis, hepatitis, adrenal insufficiency, diabetes mellitus, and skin toxicities (16). Despite these promising results, however, pembrolizumab failed to meet its pre-specified primary endpoint of overall survival in the larger phase III KEYNOTE-040 clinical trial, which compared treatment with pembrolizumab at a fixed dose of $200 \mathrm{mg}$ every 3 weeks with cetuximab, methotrexate (ESMO 2017 Press Release). Another phase III KEYNOTE trial (KEYNOTE-048, NCT02358031) is currently underway in which pembrolizumab alone (fixed $200 \mathrm{mg}$ dose in 3 weekly cycles for up to 24 months), or pembrolizumab (fixed $200 \mathrm{mg}$ dose) together with a platinumbased therapy plus 5-fluorouracil and compared with cetuximab combined with a platinum-based therapy and 5-flurouracil. The primary completion date for this trial is 31st December 2018. In addition, more than 50 clinical trials involving pembrolizumab in HNSCC are underway, most of which are focussed on therapies that combine radiotherapy or platinum-based therapies with pembrolizumab.

Nivolumab, a fully human $\mathrm{IgG}_{4}$ was also FDA approved in 2016 following completion of the CheckMate-141 openlabel, phase III clinical trial in which 361 HNSCC patients with recurrent squamous-cell carcinoma of the head and neck whose disease had progressed within 6 months after platinum-based chemotherapy, were treated with nivolumab or standard therapy alone (17). Patients received nivolumab at a dose of $3 \mathrm{mg} / \mathrm{kg}$ every 2 weeks with the end point of overall survival as the critical marker of improvement over the standard of care therapy. Patients receiving nivolumab were compared at a 2:1 ratio with patients receiving postplatinum standard of care therapies including methotrexate, docetaxel and cetuximab (17). Patients receiving nivolumab had an overall survival median of 7.5 months [95\% confidence interval [CI], 5.5 to 9.1 ] in the nivolumab group compared with 5.1 months (95\% CI, 4.0 to 6.0 ) in the standard-therapy group (17). PD-L1 expression levels were examined in $72 \%$ of the 361 patients in the clinical study and $57.1 \%$ of those had PD-L1 expression levels of $\geq 1 \%$. Individuals with PDL1 levels $\geq 1 \%$ responded better to nivolumab compared with the patient cohort in which PD-L1 was less than $1 \%$ (17). Patients specifically with oropharyngeal HNSCC also responded better to nivolumab independent of their HPV status. This study also revealed that quality of life measures in patients receiving nivolumab remained stable or improved slightly, whereas patients receiving standard therapy suffered significant deterioration at 15 weeks after commencement of therapy (17). Toxicities included pneumonitis, dermatitis, and endocrine dysfunction, although serious adverse events were significantly lower in the nivolumab compared with standard care study arm (17). As for pembrolizumab, nivolumab is currently the subject of several further clinical trials, primarily in which it is paired with other treatment options including anti-CTLA-4 ipilimumab (84).

\section{ANTI-PD-L1 ANTIBODIES}

The most recently FDA approved CI antibodies are three antiPD-L1 antibodies-atezolizumab, avelumab and durvalumab; approved for urothelial/bladder cancer (6-8), non-small cell lung cancer (atezolizumab, durvalumab) and Merkel cell carcinoma (avelumab). All of these therapies rely on expression of PD-L1 on the target tumor, allowing both patient stratification through increased response frequency based on tumor expression levels of PD-L1.

Atezolizumab, a humanized $\operatorname{IgG}_{1}$ antibody engineered to reduce any potential for $\mathrm{ADCC}$ or $\mathrm{CDC}$, was the first anti-PD-L1 antibody to be approved for use in advanced urothelial carcinoma patients whose disease had worsened after a platinum-based therapy (6). Bladder tumors have relatively high expression levels of PD-L1 compared with other tumors identifying this type of cancer as a suitable target for anti-PD-L1 antibodies (85). Patients in this phase II clinical trial were segregated according to tumorinfiltrating immune cell and tumor levels of PD-L1 expression by immunohistochemistry using the Ventana SP142 assay (6). Immune cell (IC) PD-L1 status was grouped into IC0 ( $<1 \%)$, IC1 $(\geq 1 \%$ but $<5 \%)$ and IC2/3 $(\geq 5 \%)$. Over $26 \%$ of patients with PD-L1 positive tumor TIL experienced an anti-tumor response compared with 9.5\% negative for PD-L1 supporting need for PD-L1 screening.

Avelumab, a fully human $\mathrm{IgG}_{1}$ antibody with retained potential to induce ADCC, was first approved for the treatment of Merkel cell carcinoma (MCC) (7), an aggressive cancer associated with polyomavirus infection with poor prognosis, ineffective chemotherapeutic options and low survival compared with other skin cancers. Avelumab therapy increased significantly overall survival, progression-free survival and durability of response compared with chemotherapy (7). The efficacy of avelumab was independent of PD-L1 tumor expression or polyomavirus infection (7).

Durvalumab, a fully human IgG1 engineered to reduce ADCC or CDC, was first approved for the treatment of urothelial 
carcinoma followed by approval for stage III unresectable NSCLC $(8,86)$.

For HNSCC, all three anti-PD-L1 antibodies are currently in clinical trials and in nearly all cases they are being combined with other experimental or established therapies.

\section{COMBINATION THERAPY}

Although all of the current six CI therapies can be used as single agent therapeutics, the emphasis now is on identifying combinations of CI therapy or CI therapy with other traditional therapies that will increase both anti-tumor efficacy and patient response frequency. Since 2015, many combination therapies have increased patient responses compared with single CI therapies alone. In metastatic melanoma, combination of nivolumab and ipilimumab (87) were significantly more effective in generating productive shrinkage of tumors in a higher frequency of patients than either of the CI therapeutics alone. For HNSCC, there are $>100$ clinical trials registered and most of those are combination therapies (Figures 4, 5). The predominant partner therapy for anti-PD-1 and PDL1 antibody therapies is radiotherapy in either stereotactic body or intensity modulated forms, which is often further supported by established chemotherapy. Radiotherapy seems a particularly good partner for CI therapies, because it can expose tumor-associated neoantigens that in turn can induce the nascent effector $\mathrm{T}$ cell responses that develop under cover of checkpoint blockade $(88,89)$. With regard to surgery followed by radiotherapy and standard chemotherapy, there is an interesting dichotomy of how checkpoint inhibitors have been combined in current clinical trials. While one strategy is to administer either anti-PD-1 (pembrolizumab) or PD-L1 (durvalumab) antibodies in the weeks prior to resection, another strategy is to administer these checkpoint inhibitors just after surgery. Presumably, the strategy of administration prior to surgery is based on the notion that pre-treatment will prime an anti-tumor immunity to enable the immune system to clear any residual tumor cells missed during the surgical procedure. Anti-PD-L1 antibody, durvalumab, is notable for its entry into several HNSCC clinical trials together with tremelimumab, the anti-CTLA-4 mAb (see Figure 5).

Anti-PD-1 and PD-L1 antibodies are also in clinical trials in combination with a wide range of experimental treatments that can be broadly divided into therapies that either target and activate host immunity or target and impair tumor survival. Inhibitors that target the enzyme indoleamine 2,3 dioxygenase (IDO) $(90,91)$, which is used by regulatory immune cells to deplete tryptophan availability to effector T cells, are particularly notable in these experimental combination therapies. In a similar vein, Toll-like receptor agonists, receptive to nucleic acids are also well-represented. Recent evidence suggests the endoplasmic reticulum associated DNA sensor stimulator of interferon genes (STING) to be a key player in a pathway to sense cytosolic nucleic acids $(92,93)$ and reverse tumor immunosuppression (94). DC activation through the STING pathway can promote tumor rejection after conventional cancer therapies such as

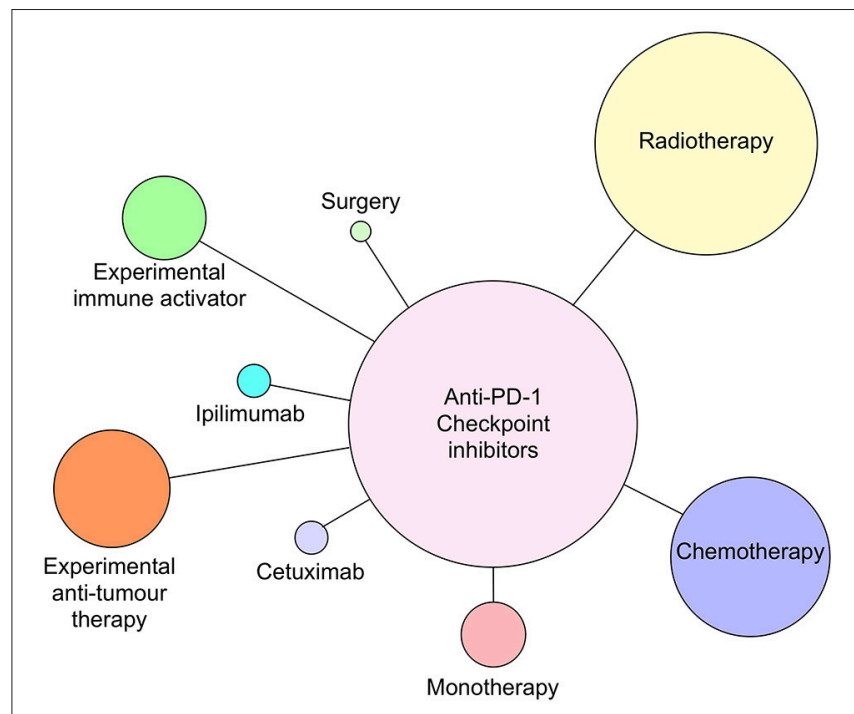

FIGURE 4 | Anti-PD-1 antibodies pembrolizumab and nivolumab currently in clinical trials as monotherapy or combined with radiotherapy, chemotherapy, cetuximab, ipilimumab (anti-CTLA-4), surgery, or novel immune activating or tumor suppressive therapies as of July 2018. Circle size reflects relative number of times each type of therapy has been combined with anti-PD-1 therapy.

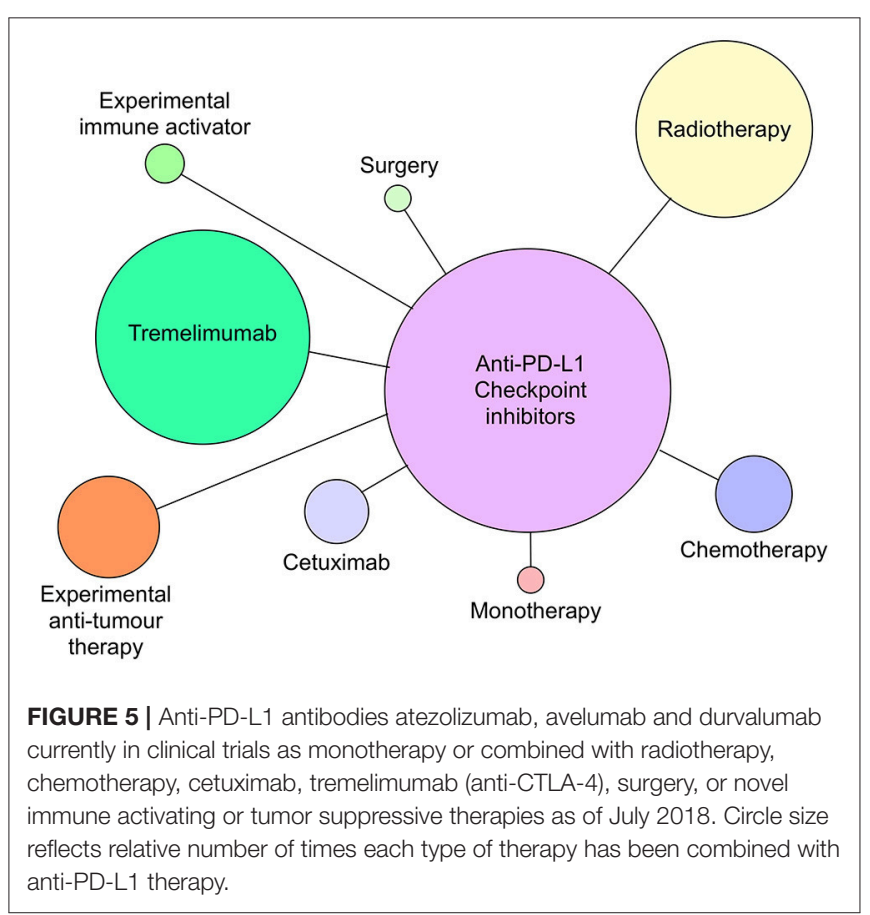

radiation therapy (95). In preclinical studies, STING agonists have been shown to be effective alone or in combination with PD-1/PD-L1 blockade, particularly with established tumors that are refractory to checkpoint blockade alone $(96,97)$. Signalling cascade inhibitors, e.g., PI3K inhibitors $(98,99)$ or novel tumor associated peptides are examples of therapies that target tumor cells (100). 
CI therapies in combination with other immune activating therapies offer the potential to increase response rates for a range of cancers including HNSCC, but there will also be intense focus on immune related adverse events, especially with regard to both bystander damage of otherwise healthy tissues and to local peritumoral tissues. This will be particularly important for HNSCC given the delicacy of many of the structures within and surrounding the oral cavity and oropharynx. Analysis of safety in patients with renal cell carcinoma that received different combination doses of nivolumab and ipilimumab indicated that the frequency of treatment related adverse effects were ubiquitous but manageable (101). Very few of the adverse events, however, were specific to the tumor site and were typically general, e.g., diarrhea and pyrexia (101).

\section{OTHER CI THERAPIES}

CTLA-4 and PD-1 are not the only immunoregulatory receptors associated with anti-tumor $\mathrm{T}$ cell immunity. There are several more checkpoint proteins under investigation, which may have direct therapeutic use or might be used to improve patient stratification and prognosis. These can be divided into two categories-immunosuppressive and immunostimulatory receptors with examples of the former being Lag-3, Tim3, TIGIT, BTLA and VISTA, and of the latter 4-1BB (CD137), OX40 (CD134), ICOS, and CD40. The expression of these receptors on tumor cells, myeloid, and lymphoid immune cells is variable and tumor dependent, and it is likely that some of them will find future therapeutic value as CI therapies (9).

\section{MODIFYING CURRENT CI THERAPIES}

The development of novel CI therapies over the next few years will continue to be an important focus and a critical aspect for future improvement is to fully elucidate how checkpoint inhibitor therapies are functioning at a molecular level. As a corollary to improving CI therapies, identifying mechanisms that will also condition $\mathrm{T}$ cells to respond consistently and effectively following CI therapy is also paramount. Much of this work involves identifying next generation vaccines or mechanisms to shape effector $\mathrm{T}$ cell phenotypes with potent anti-tumor activity. Both of these strategies will lead to higher patient response frequencies, better safety and hopefully an enduring immunity in most patients.

A generally less studied aspect of CI receptors is that of the functional effects that their soluble counterparts may have on therapeutic outcomes. These alternate receptor isoforms are either actively secreted by the cell or in some cases cleaved off the cell surface to exert their effects (102-105). Both CTLA-4 and PD-1 have soluble counterparts that are produced by alternative splicing of each gene during translation and are therefore under transcriptional control of the cell that expresses them. Soluble CTLA-4 (sCTLA-4) is produced from the omission of exon 3, encoding the transmembrane domain during alternative splicing of the CTLA-4 gene (46). In addition, a frame shift during splicing of exon 2 to 3 gives rise to a unique $\mathrm{C}$ terminal amino acid sequence that replaces the cytoplasmic domain of the CTLA4 receptor. The soluble isoform of $\mathrm{PD}-1$ (sPD-1) is also produced by omission of exon 3 during alternative splicing. These soluble isoforms may be useful as response biomarkers for patients receiving $\mathrm{CI}$ therapy but may also impinge upon the therapy itself.

Soluble CTLA- 4 is produced by Treg, but also resting $\mathrm{T}$ cells, monocytes, B cells and is capable of binding B7.1, B7.2 and B7H2 (ICOS-L) on APC (106). This secretable isoform can also be produced by some non-immune cells such as pituitary cells (107). Analysis of several autoimmune diseases originally identified high serum levels of sCTLA-4 compared with healthy donors raising the notion that this isoform actively contributes in some way to immune regulation. Indeed, selective antibody blockade of sCTLA-4 enhanced antigen-specific $\mathrm{T}$ cell responses in vitro significantly increasing cell proliferation and effector cytokine production compared with isotype or anti-CTLA-4 antibodies. Further, in the diffuse B16F10 murine model of metastatic melanoma, selective blockade had reduced the number of tumor lesions comparably with conventional anti-CTLA-4 antibody treatment (106).

The CTLA-4 receptor exists on cell surfaces as a dimer but the dimerizing cysteine residue at position 122 of the receptor isoform is lost during alternative splicing, which has led to the assumption that sCTLA-4 is secreted as a monomer and therefore has less potency that its dimeric cell-bound counterpart. However, another cysteine is present in the $\mathrm{C}$ terminal unique amino acid sequence of sCTLA-4 raising the possibility that sCTLA-4 may be as functionally relevant as the receptor isoform in terms of immune regulation.

Does sCTLA-4, therefore, have any effect on current antiCTLA-4 based CI therapy? A recent retrospective study of melanoma patient responses to ipilimumab CI therapy demonstrated that patients with relatively high serum levels of sCTLA-4 were more likely to respond to ipilimumab treatment compared to individuals with low or absent serum levels (108). Indeed, selective antibody blockade of sCTLA-4 enhanced antigen-specific $\mathrm{T}$ cell responses in vitro significantly increasing cell proliferation and effector cytokine production compared with isotype or anti-CTLA-4 antibodies (109). These studies suggest that measuring sCTLA-4 serum levels may be a useful biomarker to stratify patients most likely to respond to therapy and even hint that sCTLA-4 may form a target for therapy. Indeed, analyses of CTLA-4 and sCTLA-4 in cancer cells lines suggest that some tumors may use either or both isoforms as part of a previously overlooked immune evasion strategy (110). Several cancer cell lines and tumor sections have been identified to express CTLA-4 with some evidence that some may also be able to produce sCTLA- 4 to suppress effector $\mathrm{T}$ cell responses (64). In a seminal analysis of primary melanoma cell lines, Laurent et al. identified some cell lines to express and secrete sCTLA-4 (110). Relatively high levels of sCTLA-4 could also be detected in the sera and pleural effusions of mesothelioma patients, suggesting that it may be contributing to some aspect of immune regulation (111). One hypothesis is that tumor cells or induced Treg 
secrete sCTLA-4 within the local tumor milieu to suppress effector anti-tumor $\mathrm{T}$ cell responses. Even if sCTLA-4 has no functional activity at all, anti-CTLA-4 antibodies will bind sCTLA-4, which over time could reduce the amount of antibody available to target the receptor isoform. Although there is evidence of exosome production of PD-L1 as an immunosuppressive mechanism in HNSCC (112), the role that soluble isoforms of CI receptors play in HNSCC is still largely unexplored.

\section{CONCLUSIONS}

Checkpoint inhibitor antibodies for the treatment of HNSCC have demonstrated clear benefits in terms of patients' survival and durability of response but can also induce serious immune

\section{REFERENCES}

1. Sharma P, Allison JP. The future of immune checkpoint therapy. Science (2015) 348:56-61. doi: 10.1126/science.aaa8172

2. Schadendorf D, Hodi FS, Robert C, Weber JS, Margolin K, Hamid O, et al. Pooled Analysis of long-term survival data from Phase II and Phase III trials of Ipilimumab in unresectable or metastatic melanoma. J Clin Oncol. (2015) 33:1889-94. doi: 10.1200/JCO.2014.56.2736

3. Hodi FS, O'Day SJ, McDermott DF, Weber RW, Sosman JA, Haanen $\mathrm{JB}$, et al. Improved survival with Ipilimumab in patients with metastatic melanoma. N Engl J Med. (2010) 363:711-23. doi: 10.1056/NEJMoa100 3466

4. Robert C, Schachter J, Long GV, Arance A, Grob JJ, Mortier L, et al. Pembrolizumab versus Ipilimumab in advanced melanoma. $N$ Engl J Med. (2015) 372:2521-32. doi: 10.1056/NEJMoa1503093

5. Weber JS, D'Angelo SP, Minor D, Hodi FS, Gutzmer R, Neyns B, et al. Nivolumab versus chemotherapy in patients with advanced melanoma who progressed after anti-CTLA-4 treatment (CheckMate 037): a randomised, controlled, open-label, phase 3 trial. Lancet Oncol. (2015) 16:375-84. doi: 10.1016/S1470-2045(15)70076-8

6. Rosenberg JE, Hoffman-Censits J, Powles T, van der Heijden MS, Balar AV, Necchi A, et al. Atezolizumab in patients with locally advanced and metastatic urothelial carcinoma who have progressed following treatment with platinum-based chemotherapy: a single-arm, multicentre, phase 2 trial. Lancet (2016) 387:1909-20. doi: 10.1016/S0140-6736(16)00561-4

7. Kaufman HL, Russell J, Hamid O, Bhatia S, Terheyden P, D’Angelo SP, et al. Avelumab in patients with chemotherapy-refractory metastatic Merkel cell carcinoma: a multicentre, single-group, open-label, phase 2 trial. Lancet Oncol. (2016) 17:1374-85. doi: 10.1016/S1470-2045(16)30364-3

8. Massard C, Gordon MS, Sharma S, Rafii S, Wainberg ZA, Luke J, et al. Safety and efficacy of Durvalumab (MEDI4736), an antiprogrammed cell death Ligand-1 immune checkpoint inhibitor, in patients with advanced Urothelial Bladder cancer. J Clin Oncol. (2016) 34:3119-25. doi: 10.1200/JCO.2016.67.9761

9. Torphy RJ, Schulick RD, Zhu Y. Newly emerging immune checkpoints: promises for future cancer therapy. Int J Mol Sci. (2017) 18:E2642. doi: $10.3390 /$ ijms 18122642

10. Dougan M. Checkpoint blockade toxicity and immune homeostasis in the gastrointestinal tract. Front Immunol. (2017) 8:1547. doi: 10.3389 /fimmu.2017.01547

11. Ferlay J, Soerjomataram I, Dikshit R, Eser S, Mathers C, Rebelo M, et al. Cancer incidence and mortality worldwide: sources, methods and major patterns in GLOBOCAN 2012. Int J Cancer (2015) 136:E359-86. doi: $10.1002 /$ ijc. 29210

12. Gupta B, Johnson NW, Kumar N. Global epidemiology of head and neck cancers: a continuing challenge. Oncology (2016) 91:13-23. doi: $10.1159 / 000446117$ related adverse events coupled with an inability to consistently and accurately identify patients likely to respond to this type of therapy. The focus now must be on understanding the genetic signatures most likely to be associated with a productive response to CI therapy, while augmenting current therapies to improve their reliability. Soluble isoforms of CI receptors must also be factored to account for any immunoregulatory role or impact on current therapy that they might have.

\section{AUTHOR CONTRIBUTIONS}

All authors contributed areas of their expertise to this review. FW: CTLA-4 and sCTLA-4; LD: soluble isoforms in disease; RA-E: pathology and insights into anti-tumor immunity in HNSCC.

13. Koneva LA, Zhang Y, Virani S, Hall PB, McHugh JB, Chepeha DB, et al. HPV Integration in HNSCC correlates with survival outcomes, immune response signatures, and candidate drivers. Mol Cancer Res. (2018) 16:90102. doi: 10.1158/1541-7786.MCR-17-0153

14. Mandal R, Senbabaoglu Y, Desrichard A, Havel JJ, Dalin MG, Riaz N, et al. The head and neck cancer immune landscape and its immunotherapeutic implications. JCI Insight (2016) 1:e89829. doi: 10.1172/jci.insight. 89829

15. Brana I, Siu LL. Locally advanced head and neck squamous cell cancer: treatment choice based on risk factors and optimizing drug prescription. Ann Oncol. (2012) 23(Suppl. 10):x178-85. doi: 10.1093/annonc/mds322

16. Seiwert TY, Burtness B, Mehra R, Weiss J, Berger R, Eder JP, et al. Safety and clinical activity of pembrolizumab for treatment of recurrent or metastatic squamous cell carcinoma of the head and neck (KEYNOTE-012): an open-label, multicentre, phase 1b trial. Lancet Oncol. (2016) 17:956-65. doi: 10.1016/S1470-2045(16)30066-3

17. Ferris RL, Blumenschein G,Jr, Fayette J, Guigay J, Colevas AD, Licitra $\mathrm{L}$, et al. Nivolumab for recurrent squamous-cell carcinoma of the head and neck. N Engl J Med. (2016) 375:1856-67. doi: 10.1056/NEJMoa16 02252

18. Rizvi NA, Mazieres J, Planchard D, Stinchcombe TE, Dy GK, Antonia SJ, et al. Activity and safety of nivolumab, an anti-PD-1 immune checkpoint inhibitor, for patients with advanced, refractory squamous non-small-cell lung cancer (CheckMate 063): a phase 2, single-arm trial. Lancet Oncol. (2015) 16:257-65. doi: 10.1016/S1470-2045(15)70054-9

19. Reck M, Rodriguez-Abreu D, Robinson AG, Hui R, Csoszi T, Fulop A, et al. Pembrolizumab versus chemotherapy for PD-L1-positive non-small-cell lung cancer. $N$ Engl J Med. (2016) 375:1823-33. doi: 10.1056/NEJMoa1606774

20. Gavin M, Rudensky A. Control of immune homeostasis by naturally arising regulatory CD4+ T cells. Curr Opin Immunol. (2003) 15:690-6. doi: 10.1016/j.coi.2003.09.011

21. Greenwald RJ, Freeman GJ, Sharpe AH. The B7 family revisited. Annu Rev Immunol. (2005) 23:515-48. doi: 10.1146/annurev.immunol.23.021704.115611

22. Okazaki T, Honjo T. The PD-1-PD-L pathway in immunological tolerance. Trends Immunol. (2006) 27:195-201. doi: 10.1016/j.it.2006.02.001

23. Riley JL. PD-1 signaling in primary T cells. Immunol Rev. (2009) 229:114-25. doi: 10.1111/j.1600-065X.2009.00767.x

24. Brunet JF, Denizot F, Luciani MF, Roux-Dosseto M, Suzan M, Mattei MG, et al. A new member of the immunoglobulin superfamily-CTLA-4. Nature (1987) 328:267-70. doi: 10.1038/328267a0.

25. Linsley PS, Wallace PM, Johnson J, Gibson MG, Greene JL, Ledbetter JA, et al. Immunosuppression in vivo by a soluble form of the CTLA- $4 \mathrm{~T}$ cell activation molecule. Science (1992) 257:792-5.

26. Krummel MF, Allison JP. CD28 and CTLA-4 have opposing effects on the response of T cells to stimulation. J Exp Med. (1995) 182:459-65. 
27. Walunas TL, Lenschow DJ, Bakker CY, Linsley PS, Freeman GJ, Green JM, et al. CTLA-4 can function as a negative regulator of T cell activation. Immunity (1994) 1:405-13.

28. Ishida Y, Agata Y, Shibahara K, Honjo T. Induced expression of PD-1, a novel member of the immunoglobulin gene superfamily, upon programmed cell death. EMBO J. (1992) 11:3887-95.

29. Freeman GJ, Long AJ, Iwai Y, Bourque K, Chernova T, Nishimura H, et al. Engagement of the PD-1 immunoinhibitory receptor by a novel B7 family member leads to negative regulation of lymphocyte activation. J Exp Med. (2000) 192:1027-34. doi: 10.1084/jem.192.7.1027

30. Dong C, Juedes AE, Temann UA, Shresta S, Allison JP, Ruddle NH, et al. ICOS co-stimulatory receptor is essential for T-cell activation and function. Nature (2001) 409:97-101. doi: 10.1038/35051100

31. DeBenedette MA, Chu NR, Pollok KE, Hurtado J, Wade WF, Kwon BS, et al. Role of 4-1BB ligand in costimulation of T lymphocyte growth and its upregulation on M12 B lymphomas by cAMP. J Exp Med. (1995) 181:985-92.

32. Godfrey WR, Fagnoni FF, Harara MA, Buck D, Engleman EG. Identification of a human OX-40 ligand, a costimulator of CD4+ T cells with homology to tumor necrosis factor. J Exp Med. (1994) 180:757-62.

33. Triebel F, Jitsukawa S, Baixeras E, Roman-Roman S, Genevee C, ViegasPequignot E, et al. LAG-3, a novel lymphocyte activation gene closely related to CD4. J Exp Med. (1990) 171:1393-405.

34. Monney L, Sabatos CA, Gaglia JL, Ryu A, Waldner H, Chernova T, et al. Th1-specific cell surface protein Tim-3 regulates macrophage activation and severity of an autoimmune disease. Nature (2002) 415:536-41. doi: $10.1038 / 415536 a$

35. Yu X, Harden K, Gonzalez LC, Francesco M, Chiang E, Irving B, et al. The surface protein TIGIT suppresses $\mathrm{T}$ cell activation by promoting the generation of mature immunoregulatory dendritic cells. Nat Immunol. (2009) 10:48-57. doi: 10.1038/ni.1674

36. Wang L, Rubinstein R, Lines JL, Wasiuk A, Ahonen C, Guo Y, et al. VISTA, a novel mouse Ig superfamily ligand that negatively regulates $\mathrm{T}$ cell responses. J Exp Med. (2011) 208:577-92. doi: 10.1084/jem.20100619

37. Watanabe N, Gavrieli M, Sedy JR, Yang J, Fallarino F, Loftin SK, et al. BTLA is a lymphocyte inhibitory receptor with similarities to CTLA-4 and PD-1. Nat Immunol. (2003) 4:670-9. doi: 10.1038/ni944

38. Nocentini G, Giunchi L, Ronchetti S, Krausz LT, Bartoli A, Moraca R, et al. A new member of the tumor necrosis factor/nerve growth factor receptor family inhibits T cell receptor-induced apoptosis. Proc Natl Acad Sci USA. (1997) 94:6216-21.

39. Marin-Acevedo JA, Dholaria B, Soyano AE, Knutson KL, Chumsri S, Lou Y. Next generation of immune checkpoint therapy in cancer: new developments and challenges. J Hematol Oncol. (2018) 11:39. doi: 10.1186/s13045-018-0582-8

40. Bethmann D, Feng Z, Fox BA. Immunoprofiling as a predictor of patient's response to cancer therapy-promises and challenges. Curr Opin Immunol. (2017) 45:60-72. doi: 10.1016/j.coi.2017.01.005

41. Feng Z, Bethmann D, Kappler M, Ballesteros-Merino C, Eckert A, Bell RB, et al. Multiparametric immune profiling in HPV-oral squamous cell cancer. JCI Insight (2017) 2:93652. doi: 10.1172/jci.insight.93652

42. Couzin-Frankel J. Breakthrough of the year 2013. Cancer immunotherapy. Science (2013) 342:1432-3. doi: 10.1126/science.342.6165.1432

43. Alexandrov LB, Nik-Zainal S, Wedge DC, Aparicio SA, Behjati S, Biankin AV, et al. Signatures of mutational processes in human cancer. Nature (2013) 500:415-21. doi: 10.1038/nature12477

44. Kaplon H, Reichert JM. Antibodies to watch in 2018. MAbs (2018) 10:183-203. doi: 10.1080/19420862.2018.14 1567

45. Riley JL, June CH. The CD28 family: a T-cell rheostat for therapeutic control of T-cell activation. Blood (2005) 105:13-21. doi: 10.1182/blood-2004-04-1596.

46. Teft WA, Kirchhof MG, Madrenas J. A molecular perspective of CTLA-4 function. Annu Rev Immunol. (2006) 24:65-97. doi: 10.1146/annurev.immunol.24.021605.090535

47. Collins AV, Brodie DW, Gilbert RJ, Iaboni A, Manso-Sancho R, Walse B, et al. The interaction properties of costimulatory molecules revisited. Immunity (2002) 17:201-10. doi: 10.1016/S1074-7613(02)00362-X
48. Sharma P, Allison JP. Immune checkpoint targeting in cancer therapy: toward combination strategies with curative potential. Cell (2015) 161:20514. doi: 10.1016/j.cell.2015.03.030

49. Tivol EA, Borriello F, Schweitzer AN, Lynch WP, Bluestone JA, Sharpe AH. Loss of CTLA-4 leads to massive lymphoproliferation and fatal multiorgan tissue destruction, revealing a critical negative regulatory role of CTLA-4. Immunity (1995) 3:541-7.

50. Waterhouse P, Penninger JM, Timms E, Wakeham A, Shahinian A, Lee KP, et al. Lymphoproliferative disorders with early lethality in mice deficient in Ctla-4. Science (1995) 270:985-8.

51. Tivol EA, Boyd SD, McKeon S, Borriello F, Nickerson P, Strom TB, et al. CTLA4Ig prevents lymphoproliferation and fatal multiorgan tissue destruction in CTLA-4-deficient mice. J Immunol. (1997) 158:5091-4.

52. Waterhouse P, Bachmann MF, Penninger JM, Ohashi PS, Mak TW. Normal thymic selection, normal viability and decreased lymphoproliferation in $\mathrm{T}$ cell receptor-transgenic CTLA-4-deficient mice. Eur J Immunol. (1997) 27:1887-92.

53. Tivol EA, Gorski J. Re-establishing peripheral tolerance in the absence of CTLA-4: complementation by wild-type T cells points to an indirect role for CTLA-4. J Immunol. (2002) 169:1852-8. doi: 10.4049/jimmunol.169.4.1852

54. Lo B, Zhang K, Lu W, Zheng L, Zhang Q, Kanellopoulou C, et al. AUTOIMMUNE DISEASE. Patients with LRBA deficiency show CTLA4 loss and immune dysregulation responsive to abatacept therapy. Science (2015) 349:436-40. doi: 10.1126/science.aaa1663

55. Schubert D, Bode C, Kenefeck R, Hou TZ, Wing JB, Kennedy A, et al. Autosomal dominant immune dysregulation syndrome in humans with CTLA4 mutations. Nat Med. (2014) 20:1410-6. doi: 10.1038/nm.3746

56. Kuehn HS, Ouyang W, Lo B, Deenick EK, Niemela JE, Avery DT, et al. Immune dysregulation in human subjects with heterozygous germline mutations in CTLA4. Science (2014) 345:1623-7. doi: 10.1126/science. 1255904

57. Wing K, Yamaguchi T, Sakaguchi S. Cell-autonomous and -non-autonomous roles of CTLA-4 in immune regulation. Trends Immunol. (2011) 32:428-33. doi: 10.1016/j.it.2011.06.002

58. Walker LS, Sansom DM. The emerging role of CTLA4 as a cell-extrinsic regulator of $\mathrm{T}$ cell responses. Nat Rev Immunol. (2011) 11:852-63. doi: $10.1038 /$ nri3108

59. Kwon ED, Hurwitz AA, Foster BA, Madias C, Feldhaus AL, Greenberg $\mathrm{NM}$, et al. Manipulation of $\mathrm{T}$ cell costimulatory and inhibitory signals for immunotherapy of prostate cancer. Proc Natl Acad Sci USA. (1997) 94:8099-103.

60. van Elsas A, Hurwitz AA, Allison JP. Combination immunotherapy of B16 melanoma using anti-cytotoxic $\mathrm{T}$ lymphocyte-associated antigen 4 (CTLA-4) and granulocyte/macrophage colony-stimulating factor (GM$\mathrm{CSF}$ )-producing vaccines induces rejection of subcutaneous and metastatic tumors accompanied by autoimmune depigmentation. J Exp Med. (1999) 190:355-66.

61. Hurwitz AA, Yu TF, Leach DR, Allison JP. CTLA-4 blockade synergizes with tumor-derived granulocyte-macrophage colony-stimulating factor for treatment of an experimental mammary carcinoma. Proc Natl Acad Sci USA. (1998) 95:10067-71.

62. Alexandrov LB, Ju YS, Haase K, Van Loo P, Martincorena I, Nik-Zainal S, et al. Mutational signatures associated with tobacco smoking in human cancer. Science (2016) 354:618-22. doi: 10.1126/science.aag0299

63. Simpson TR, Li F, Montalvo-Ortiz W, Sepulveda MA, Bergerhoff K, Arce F, et al. Fc-dependent depletion of tumor-infiltrating regulatory $\mathrm{T}$ cells co-defines the efficacy of anti-CTLA-4 therapy against melanoma. J Exp Med. (2013) 210:1695-710. doi: 10.1084/jem.20130579

64. Contardi E, Palmisano GL, Tazzari PL, Martelli AM, Fala F, Fabbi $\mathrm{M}$, et al. CTLA-4 is constitutively expressed on tumor cells and can trigger apoptosis upon ligand interaction. Int J Cancer (2005) 117:538-50. doi: $10.1002 /$ ijc. 21155

65. Laurent S, Queirolo P, Boero S, Salvi S, Piccioli P, Boccardo S, et al. The engagement of CTLA-4 on primary melanoma cell lines induces antibodydependent cellular cytotoxicity and TNF-alpha production. J Transl Med. (2013) 11:108. doi: 10.1186/1479-5876-11-108 
66. Dong H, Zhu G, Tamada K, Chen L. B7-H1, a third member of the B7 family, co-stimulates T-cell proliferation and interleukin-10 secretion. Nat Med. (1999) 5:1365-9. doi: 10.1038/70932

67. Latchman Y, Wood CR, Chernova T, Chaudhary D, Borde M, Chernova I, et al. PD-L2 is a second ligand for PD-1 and inhibits T cell activation. Nat Immunol. (2001) 2:261-8. doi: 10.1038/85330

68. Sharpe AH, Wherry EJ, Ahmed R, Freeman GJ. The function of programmed cell death 1 and its ligands in regulating autoimmunity and infection. Nat Immunol. (2007) 8:239-45. doi: 10.1038/ni1443

69. Malm IJ, Bruno TC, Fu J, Zeng Q, Taube JM, Westra W, et al. Expression profile and in vitro blockade of programmed death-1 in human papillomavirus-negative head and neck squamous cell carcinoma. Head Neck (2015) 37:1088-95. doi: 10.1002/hed.23706

70. Barber DL, Wherry EJ, Masopust D, Zhu B, Allison JP, Sharpe AH, et al. Restoring function in exhausted CD8 T cells during chronic viral infection. Nature (2006) 439:682-7. doi: 10.1038/nature04444

71. Brown JA, Dorfman DM, Ma FR, Sullivan EL, Munoz O, Wood CR, et al. Blockade of programmed death-1 ligands on dendritic cells enhances T cell activation and cytokine production. J Immunol. (2003) 170:1257-66. doi: 10.4049/jimmunol.170.3.1257

72. Fife BT, Bluestone JA. Control of peripheral T-cell tolerance and autoimmunity via the CTLA-4 and PD-1 pathways. Immunol Rev. (2008) 224:166-82. doi: 10.1111/j.1600-065X.2008.00662.x.

73. Thompson RH, Dong H, Lohse CM, Leibovich BC, Blute ML, Cheville JC, et al. PD-1 is expressed by tumor-infiltrating immune cells and is associated with poor outcome for patients with renal cell carcinoma. Clin Cancer Res. (2007) 13:1757-61. doi: 10.1158/1078-0432.CCR-06-2599

74. Strome SE, Dong H, Tamura H, Voss SG, Flies DB, Tamada K, et al. B7H1 blockade augments adoptive T-cell immunotherapy for squamous cell carcinoma. Cancer Res. (2003) 63:6501-5.

75. Dong H, Strome SE, Salomao DR, Tamura H, Hirano F, Flies DB, et al. Tumor-associated B7-H1 promotes T-cell apoptosis: a potential mechanism of immune evasion. Nat Med. (2002) 8:793-800. doi: 10.1038/nm730

76. Ohigashi Y, Sho M, Yamada Y, Tsurui Y, Hamada K, Ikeda N, et al. Clinical significance of programmed death-1 ligand-1 and programmed death-1 ligand-2 expression in human esophageal cancer. Clin Cancer Res. (2005) 11:2947-53. doi: 10.1158/1078-0432.CCR-04-1469

77. Kim HR, Ha SJ, Hong MH, Heo SJ, Koh YW, Choi EC, et al. PDL1 expression on immune cells, but not on tumor cells, is a favorable prognostic factor for head and neck cancer patients. Sci Rep. (2016) 6:36956. doi: $10.1038 /$ srep36956

78. Lyford-Pike S, Peng S, Young GD, Taube JM, Westra WH, Akpeng B, et al. Evidence for a role of the PD-1:PD-L1 pathway in immune resistance of HPV-associated head and neck squamous cell carcinoma. Cancer Res. (2013) 73:1733-41. doi: 10.1158/0008-5472.CAN-12-2384

79. Ou D, Adam J, Garberis I, Blanchard P, Nguyen F, Levy A, et al. Clinical relevance of tumor infiltrating lymphocytes, PD-L1 expression and correlation with HPV/p16 in head and neck cancer treated with bio- or chemo-radiotherapy. Oncoimmunology (2017) 6:e1341030. doi: 10.1080/2162402X.2017.1341030

80. Dahan R, Sega E, Engelhardt J, Selby M, Korman AJ, Ravetch JV. FcgammaRs modulate the anti-tumor activity of antibodies targeting the PD-1/PD-L1 axis. Cancer Cell (2015) 28:285-95. doi: 10.1016/j.ccell.2015. 08.004

81. Franklin C, Livingstone E, Roesch A, Schilling B, Schadendorf D. Immunotherapy in melanoma: recent advances and future directions. Eur J Surg Oncol (2017) 43:604-611. doi: 10.1016/j.ejso.2016.07.145

82. Ribas A, Puzanov I, Dummer R, Schadendorf D, Hamid O, Robert C, et al. Pembrolizumab versus investigator-choice chemotherapy for ipilimumabrefractory melanoma (KEYNOTE-002): a randomised, controlled, phase 2 trial. Lancet Oncol. (2015) 16:908-18. doi: 10.1016/S1470-2045(15) 00083-2

83. Chow LQM, Haddad R, Gupta S, Mahipal A, Mehra R, Tahara M, et al. Antitumor Activity of Pembrolizumab in Biomarker-Unselected Patients With Recurrent and/or Metastatic Head and Neck Squamous Cell Carcinoma: Results From the Phase Ib KEYNOTE-012 Expansion Cohort. J Clin Oncol. (2016) 34:3838-45. doi: 10.1200/JCO.2016. 68.1478
84. Schwab KS, Kristiansen G, Schild HH, Held SEA, Heine A, Brossart P. Successful Treatment of Refractory Squamous Cell Cancer of the Head and Neck with Nivolumab and Ipilimumab. Case Rep Oncol (2018) 11:17-20. doi: 10.1159/000485562

85. Nakanishi J, Wada Y, Matsumoto K, Azuma M, Kikuchi K, Ueda S. Overexpression of B7-H1 (PD-L1) significantly associates with tumor grade and postoperative prognosis in human urothelial cancers. Cancer Immunol Immunother. (2007) 56:1173-82. doi: 10.1007/s00262-006-0266-Z

86. Antonia SJ, Villegas A, Daniel D, Vicente D, Murakami S, Hui R, et al. Durvalumab after Chemoradiotherapy in stage III Non-small-cell lung cancer. N Engl J Med. (2017) 377:1919-29. doi: 10.1056/NEJMoa1709937

87. Larkin J, Chiarion-Sileni V, Gonzalez R, Grob JJ, Cowey CL, Lao CD, et al. Combined Nivolumab and Ipilimumab or Monotherapy in untreated melanoma. N Engl J Med. (2015) 73:23-34. doi: 10.1056/NEJMoa1504030

88. Matsushita H, Vesely MD, Koboldt DC, Rickert CG, Uppaluri R, Magrini VJ, et al. Cancer exome analysis reveals a T-cell-dependent mechanism of cancer immunoediting. Nature (2012) 482:400-4. doi: 10.1038/nature10755

89. McGranahan N, Furness AJ, Rosenthal R, Ramskov S, Lyngaa R, Saini SK, et al. Clonal neoantigens elicit $\mathrm{T}$ cell immunoreactivity and sensitivity to immune checkpoint blockade. Science (2016) 351:1463-9. doi: 10.1126/science.aaf1490

90. Friberg M, Jennings R, Alsarraj M, Dessureault S, Cantor A, Extermann M, et al. Indoleamine 2,3-dioxygenase contributes to tumor cell evasion of $\mathrm{T}$ cell-mediated rejection. Int J Cancer (2002) 101:151-5. doi: 10.1002/ijc.10645

91. Munn DH, Sharma MD, Hou D, Baban B, Lee JR, Antonia SJ, et al. Expression of indoleamine 2,3-dioxygenase by plasmacytoid dendritic cells in tumor-draining lymph nodes. J Clin Invest. (2004) 114:280-90. doi: 10.1172/JCI21583

92. Wu J, Sun L, Chen X, Du F, Shi H, Chen C, et al. Cyclic GMPAMP is an endogenous second messenger in innate immune signaling by cytosolic DNA. Science (2013) 339:826-30. doi: 10.1126/science.12 29963

93. Woo SR, Fuertes MB, Corrales L, Spranger S, Furdyna MJ, Leung MY, et al. STING-dependent cytosolic DNA sensing mediates innate immune recognition of immunogenic tumors. Immunity (2014) 41:830-42. doi: 10.1016/j.immuni.2014.10.017

94. Dahal LN, Dou L, Hussain K, Liu R, Earley A, Cox KL, et al. STING Activation reverses Lymphoma-mediated resistance to antibody immunotherapy. Cancer Res (2017) 77:3619-31. doi: 10.1158/0008-5472.CAN-16-2784

95. Baird JR, Friedman D, Cottam B, Dubensky TW,Jr, Kanne DB, Bambina S, et al. Radiotherapy combined with novel STING-targeting oligonucleotides results in regression of established tumors. Cancer Res. (2016) 76:50-61. doi: 10.1158/0008-5472.CAN-14-3619

96. Deng L, Liang H, Xu M, Yang X, Burnette B, Arina A, et al. STINGDependent Cytosolic DNA sensing promotes radiation-induced type i interferon-dependent antitumor immunity in immunogenic tumors. Immunity (2014) 41:843-52. doi: 10.1016/j.immuni.2014.10.019

97. Fu J, Kanne DB, Leong M, Glickman LH, McWhirter SM, Lemmens E, et al. STING agonist formulated cancer vaccines can cure established tumors resistant to PD-1 blockade. Sci Transl Med. (2015) 7:283ra52. doi: 10.1126/scitranslmed.aaa4306

98. Abu-Eid R, Samara RN, Ozbun L, Abdalla MY, Berzofsky JA, Friedman $\mathrm{KM}$, et al. Selective inhibition of regulatory $\mathrm{T}$ cells by targeting the PI3K-Akt pathway. Cancer Immunol Res. (2014) 2:1080-9. doi: 10.1158/2326-6066.CIR-14-0095

99. Abu Eid R, Ahmad S, Lin Y, Webb M, Berrong Z, Shrimali R, et al. Enhanced therapeutic efficacy and memory of tumor-specific CD8 T Cells by Ex Vivo PI3K-delta inhibition. Cancer Res. (2017) 77:4135-45. doi: 10.1158/0008-5472.CAN-16-1925

100. Gill K, Nigam L, Singh R, Kumar S, Subbarao N, Chauhan SS, et al. The rational design of specific peptide inhibitor against p38alpha MAPK at allosteric-site: a therapeutic modality for HNSCC. PLoS ONE (2014) 9:e101525. doi: 10.1371/journal.pone.0101525

101. Hammers HJ, Plimack ER, Infante JR, Rini BI, McDermott DF, Lewis LD, et al. Safety and efficacy of Nivolumab in combination with Ipilimumab in metastatic renal cell carcinoma: the checkmate 016 study. J Clin Oncol. (2017) 35:3851-8. doi: 10.1200/JCO.2016.72.1985 
102. Magistrelli G, Jeannin P, Herbault N, Benoit De Coignac A, Gauchat JF, Bonnefoy JY, et al. A soluble form of CTLA-4 generated by alternative splicing is expressed by nonstimulated human T cells. Eur J Immunol. (1999) 29:3596-602. doi: 10.1002/(SICI)1521-4141(199911)29:113.0.CO;2-Y

103. Oaks MK, Hallett KM, Penwell RT, Stauber EC, Warren SJ, Tector AJ. A native soluble form of CTLA-4. Cell Immunol. (2000) 201:144-53. doi: 10.1006/cimm.2000.1649

104. Oaks MK, Hallett KM. Cutting edge: a soluble form of CTLA-4 in patients with autoimmune thyroid disease. J Immunol. (2000) 164:5015-8. doi: 10.4049/jimmunol.164.10.5015

105. Liu C, Jiang J, Gao L, Wang X, Hu X, Wu M, et al. Soluble PD-1 aggravates progression of collagen-induced arthritis through Th1 and Th17 pathways. Arthritis Res Ther. (2015) 17:340. doi: 10.1186/s13075-015-0859-z

106. Ward FJ, Dahal LN, Khanolkar RC, Shankar SP, Barker RN. Targeting the alternatively spliced soluble isoform of CTLA-4: prospects for immunotherapy? Immunotherapy (2014) 6:1073-84. doi: 10.2217/imt.14.73

107. Iwama S, De Remigis A, Callahan MK, Slovin SF, Wolchok JD, Caturegli P. Pituitary expression of CTLA-4 mediates hypophysitis secondary to administration of CTLA-4 blocking antibody. Sci Transl Med. (2014) 6:230ra45. doi: 10.1126/scitranslmed.3008002

108. Leung AM, Lee AF, Ozao-Choy J, Ramos RI, Hamid O, O’Day SJ, et al. Clinical Benefit from Ipilimumab therapy in melanoma patients may be associated with serum CTLA4 levels. Front Oncol. (2014) 4:110. doi: $10.3389 /$ fonc. 2014.00110

109. Ward FJ, Dahal LN, Wijesekera SK, Abdul-Jawad SK, Kaewarpai T, $\mathrm{Xu} \mathrm{H}$, et al. The soluble isoform of CTLA-4 as a regulator of Tcell responses. Eur J Immunol. (2013) 43:1274-85. doi: 10.1002/eji.2012 42529
110. Laurent S, Carrega P, Saverino D, Piccioli P, Camoriano M, Morabito A, et al. CTLA-4 is expressed by human monocyte-derived dendritic cells and regulates their functions. Hum Immunol. (2010) 71:934-41. doi: 10.1016/j.humimm.2010.07.007

111. Roncella S, Laurent S, Fontana V, Ferro P, Franceschini MC, Salvi S, et al. CTLA-4 in mesothelioma patients: tissue expression, body fluid levels and possible relevance as a prognostic factor. Cancer Immunol Immunother. (2016) 65:909-17. doi: 10.1007/s00262-016-1844-3

112. Theodoraki MN, Yerneni SS, Hoffmann TK, Gooding WE, Whiteside TL. Clinical significance of PD-L1(+) Exosomes in plasma of head and neck cancer patients. Clin Cancer Res. (2018) 24:896-905. doi: 10.1158/1078-0432.CCR-17-2664

Conflict of Interest Statement: FW and LD are shareholders in Aperio Pharma Ltd., a spin-out company currently developing a novel checkpoint inhibitor antibody.

The remaining author declares that the research was conducted in the absence of any commercial or financial relationships that could be construed as a potential conflict of interest.

Copyright (C) 2018 Ward, Dahal and Abu-Eid. This is an open-access article distributed under the terms of the Creative Commons Attribution License (CC BY). The use, distribution or reproduction in other forums is permitted, provided the original author(s) and the copyright owner(s) are credited and that the original publication in this journal is cited, in accordance with accepted academic practice. No use, distribution or reproduction is permitted which does not comply with these terms. 